\title{
Batabulin Sodium
}

National Cancer Institute

\section{Source}

National Cancer Institute. Batabulin Sodium. NCI Thesaurus. Code C1835.

The sodium salt form of batabulin, a synthetic pentafluorophenylsulfonamide with potential antineoplastic activity. Batabulin covalently binds to and selectively modifies the beta 1 , beta 2 , beta 3 , and beta 4 isotypes of beta tubulin at a conserved cysteine residue, resulting in disruption of microtubule polymerization, collapse of the cytoskeleton, an increase in chromosomal ploidy, cell cycle arrest, and tumor cell apoptosis. 